\title{
UNA APROXIMACIÓN A LOS INSTRUMENTOS ECONÓMICOS DE LAS LEYES DEL SUELO DEL 2008 Y 2015. ¿HACIA UN CAMBIO EN EL MODELO DE DESARROLLO EN ESPAÑA? ${ }^{1}$
}

\author{
José Antonio Sotelo Navalpotro \\ Instituto Universitario de Ciencias Ambientales (IUCA/UCM) \\ jasotelo@ucm.es \\ María Sotelo Pérez ${ }^{2}$ \\ Departamento de Análisis Geográfico Regional y Geografía Física (UCM) \\ Grupo de Investigación: "Desarrollo y Gestión Ambiental del Territorio" \\ maria.sotelo.perez@ucm.es \\ Ignacio Sotelo Pérez ${ }^{3}$ \\ Instituto Universitario de Ciencias Ambientales (IUCA/UCM) \\ Grupo de Investigación: "Desarrollo y Gestión Ambiental del Territorio" \\ ignaciosoteloperez@ucm.es
}

\section{RESUMEN}

Tras la aprobación del Real Decreto Legislativo 2/2008 -Ley del Suelo-, nos encontramos ante un modelo territorial y un modelo de desarrollo, que acaba con el arcaico patrón de ciudad dispersa, encontrándose, no obstante, ante las gravísimas consecuencias espaciales generadas por la denominada "burbuja inmobiliaria", unida a una crisis de consecuencias insospechadas, en el ámbito de la denominada globalización económica, de la que nuestro país no ha logrado sustraerse con Leyes vacías de instrumentos económicos que se han transferido a las Comunidades Autónomas, nos hallamos ante una oportunidad perdida fruto de una no siempre bien calculada descentralización. De este modo, en el presente artículo nos aproximamos a la importancia que muestran los denominados "instrumentos económicos" en la normativa que recoge los pormenores relacionados con el "suelo", en España, en la primera de nuestras Leyes, la de 1956, en la de 2008 y en el recién aprobado Texto Refundido de la Ley del Suelo y Rehabilitación Urbana -Real Decreto Legislativo 7/2015-, en el ámbito estatal. Para ello, tras definir y valorar los enfoques conceptuales relativos al "suelo" y sus tipologías, se concretan y estudian los instrumentos económicos que se recogen en la Ley del Suelo española y su relación con las nuevas formas de "hacer ciudad".

Palabras clave: Instrumentos económicos; Leyes del Suelo; urbanización compacta; Modelos territoriales; Modelos de desarrollo.

\section{ABSTRACT \\ An approach to the economic instruments of the Land Acts of 2008 and 2015. Towards a change in the Development Model in Spain?}

Following the approval of Royal Decree 2/2008 - the Land Act - we have a territorial model and a model for development which has put an end to the archaic pattern of the dispersed city, although we are faced with very serious consequences of space generated by the so-called "housing bubble", coupled with a crisis of unforeseeable consequences in the field of so-called economic globalization. Spain has not

\footnotetext{
1 Grupo de Investigación de la Universidad Complutense de Madrid: "Desarrollo y Gestión Ambiental del Territorio" (UCM-930539). La presente investigación se enmarca en el Proyecto de Investigación MINECO (2014).CTM2013-41750-P.

2 Investigadora Contratada FPU (Formación del Profesorado Universitario). Ministerio de Educación, Cultura y Deporte.

3 Investigador Contratado Predoctoral UCM.
} 
managed to escape from this with laws devoid of economic instruments that have been transferred to the Autonomous Communities, and we are facing a missed opportunity resulting from a not always well-calculated decentralization. Thus, in this article, we approach the importance demonstrated by the so-called "economic instruments" in the regulations, which include the details relating to "land" in Spain in our first law, of 1956, in that of 2008 and in the recently approved revised text of the Land and Urban Rehabilitation Act - Royal Legislative Decree 7/2015 - at state level. To this end, after defining and assessing the conceptual approaches to "land" and their types, the study specifies and studies the economic instruments included in the Spanish Land Act and their relationship with the new forms of "city building".

Key words: Economic instruments; Land Act; compact development; territorial models; development models.

\section{INTRODUCCIÓN}

La creciente degradación ambiental que acompaña al aumento de actividades económicas guiadas sólo por intereses monetarios; las persistentes desigualdades entre los hombres y las mujeres -que siguen cargando con el "invisible" trabajo no remunerado-, y la pobreza de gran parte de la humanidad, ignorada cuando no agravada por las instituciones internacionales son realidades a las que, en España, en los últimos años se añaden tres "T" de "insostenibilidad": el transporte, el turismo y el territorio. No debemos olvidarnos que España mantiene "tendencias insostenibles" desde el punto de vista del medio ambiente, al registrarse problemas "preocupantes" de cambio climático vinculado con la energía, así como un modelo de desarrollo económico basado en muchos casos en "costes" sociales y ambientales importantes, si bien el "punto crítico" de la sostenibilidad en nuestro país se halla en la "mala gestión" territorial (podemos afirmar que en nuestro país se ha malgastado y se despilfarra "territorio". A pesar de que se elaboran multitud de leyes y directrices territoriales para frenar la saturación urbanística, en muchas ocasiones éstas no van seguidas de desarrollos normativos que permitan su aplicación, convirtiéndolas en papel mojado. En algunas Comunidades Autónomas, como en Galicia, la política urbanística va encaminada a no tomar medidas a escala regional, coadyuvando así a las más diversas actuaciones municipales carentes de criterios de planificación territorial. En otras, como Andalucía, los planes territoriales acumulan décadas de retraso, permitiendo la saturación urbanística. También encontramos casos tan graves como el de la Comunidad Valenciana, donde la Comisión Europea está investigando la normativa urbanística por estar acusada de estimular el favoritismo y la corrupción en los contratos públicos ${ }^{4}$.

En definitiva, la gestión prudente del territorio debe convertirse en el elemento central de un nuevo debate ciudadano. Un debate democrático en el que participen todos los actores concernidos, especialmente aquellos que menos capacidad tienen para hacer oír su voz. Es imprescindible que la sociedad española tome conciencia de que, de persistir, el mal uso y desgobierno del territorio acarrearía, tras una corta etapa de grandes beneficios privados, largos periodos de onerosos costes ambientales, económicos y sociales. Tras la aprobación de la actual Ley del Suelo del $2008^{5}$, base de la nueva Ley del Suelo del $2015^{6}$, nos encontramos ante un modelo territorial urbano, que acaba con el arcaico patrón de ciudad dispersa ${ }^{7}$, como consecuencia de una nueva economía basada en la terciarización, la diversificación y la flexibili-

4 Es de interés, consultar, al respecto, los siguientes trabajos: Sotelo Navalpotro, (1999); Sotelo Navalpotro, Tolón Becerra y Lastra Bravo, (2011); Bouazza Ariño, O. (2006); Bouazza Ariño, O. (2009); Martín Matero, R. (2007).

5 Real Decreto Legislativo 2/2008, de 20 de junio, por el que se aprueba el texto refundido de la Ley de suelo. La Disposición final segunda de la Ley 8/2007, de 28 de mayo, de Suelo, delegó en el Gobierno la potestad de dictar un Real Decreto Legislativo que refundiera el texto de ésta y los preceptos que aún quedaban vigentes del Real Decreto Legislativo 1/1992, de 26 de junio, por el que se aprobó el Texto Refundido de la Ley sobre Régimen del Suelo y Ordenación Urbana. El plazo para la realización de dicho texto era de un año, a contar desde la entrada en vigor de aquélla.

6 El Real Decreto Legislativo 7/2015, de 30 de octubre, por el que se aprueba el texto refundido de la Ley de Suelo y Rehabilitación Urbana (vigente Ley del Suelo), aúna la Ley del Suelo del 2008 y la Ley 8/2013, de 26 de junio, de rehabilitación, regeneración y renovación urbanas (conocida como, Ley de las "tres R").

7 TRLS 2/2008 establece que:

la historia del Derecho urbanístico español contemporáneo se forjó en la segunda mitad del siglo XIX, en un contexto socio-económico de industrialización y urbanización, en torno a dos grandes tipos de operaciones urbanísticas: el ensanche y la reforma interior, la creación de nueva ciudad y el saneamiento y la reforma de la existente. Dicha historia cristalizó a mediados del siglo XX con la primera ley completa en la materia, de la que sigue siendo tributaria nuestra tradición posterior. En efecto, las grandes instituciones urbanísticas actuales conservan una fuerte inercia respecto de las concebidas entonces: la clasificación del suelo como técnica por excelencia de la que se valen tanto la ordenación como la ejecución urbanísticas suelo rústico o no urbanizable no merece apenas atención por jugar un papel exclusivamente negativo o residual; la instrumentación de la ordenación mediante un sistema rígido de desagregación sucesiva de planes; la ejecución de dichos planes prácticamente identificada con la urbanización sistemática, que puede ser acometida mediante formas de gestión pública o privada, a través de un conjunto de sistemas de actuación. 
zación de las actividades económicas, los bienes y servicios, y la incorporación, tanto en las economías domésticas como en las empresas, de las nuevas tecnologías de la información. Mediante la Ley del Suelo 2/2008 se pretende terminar con el tradicional impulso desarrollista de las últimas décadas, basado en un crecimiento urbano ilimitado, y, favorecer la regeneración de la ciudad existente, frente a las nuevas transformaciones de suelo -teniendo en cuenta que la legislación estatal no se puede imponer un determinado modelo urbanístico.

La transición hacia una morfología urbana compacta a partir de una estructura espacial discontinua se viene consolidando, desde los últimos años del pasado siglo; lo que ha propiciado notables transformaciones territoriales que se han traducido en cambios en la organización territorial a través de las infraestructuras del transporte que han organizado y mejorado los flujos de movilidad, y, modificaciones en la localización de las actividades económicas y de los sectores productivos. Por ello, a tenor de lo expuesto, era evidente la necesidad de establecer nuevos modelos de planeamiento urbanístico que den respuesta a estos cambios económicos, sociales, territoriales, ambientales y políticos.

De este modo, el objeto de la Ley, recogido en el art. 1 del TRLS 2/2008, establece que la

Ley regula las condiciones básicas que garantizan la igualdad en el ejercicio de los derechos y en el cumplimiento de los deberes constitucionales relacionados con el suelo en todo el territorio estatal.

Asimismo, establece las bases económicas y medioambientales de su régimen jurídico, su valoración y la responsabilidad patrimonial de las Administraciones Públicas en la materia.

Y es que, durante las últimas décadas, tal y como se refleja en el Texto Refundido de la Ley del Suelo 2/2008 "el urbanismo español contemporáneo es una historia desarrollista, volcada sobre todo en la creación de nueva ciudad", se ha concebido el suelo, exclusivamente, como un mero recurso económico ${ }^{8}$. Fiel reflejo de ello lo encontramos en la falta de planeamiento urbanístico existente hoy día en nuestro país. Por ello, en el TRLS 2/2008 se estipula que "el suelo es un recurso económico, natural, escaso y no renovable".

Desde esta perspectiva, todo el suelo rural tiene un valor ambiental que hay que estimar, con lo que la liberalización de este no puede fundamentarse en una clasificación indistinto y confuso, sino, en una clasificación responsable del suelo urbanizable con el que hacer frente a las necesidades sociales, económicas y ambientales, a la hora de liberalizar el uso del mismo para su urbanización, en contra las prácticas especulativas, de manera que el suelo urbano obtenga un uso eficiente y efectivo. Y que el suelo urbano ya existente tenga un valor ambiental, "como creación cultural colectiva que es objeto de una permanente recreación, por lo que sus características deben ser expresión de su naturaleza y su ordenación debe favorecer su rehabilitación y fomentar su uso" (TRLS 2/2008), tal y como se recoge en la propia Ley.

\subsection{Objetivos y metodología}

El presente estudio tiene por objeto aproximarse a la importancia que presentan los denominados "instrumentos económicos" en la normativa que recoge los pormenores relacionados con el "suelo", en España, en la primera de nuestras Leyes, la de 1956, y en la por el momento última, la de 2008, -así como en el recién aprobado Texto Refundido de la Ley del Suelo y Rehabilitación Urbana, Real Decreto Legislativo 7/2015-, en el ámbito estatal. De igual modo, la presente investigación se ha llevado a cabo a través de la consulta de fondos bibliográficos, archivos, guías nacionales, artículos científicos, revistas especializadas, bases de datos, informes oficiales, así como la legislación relativa a los temas tratados. A su vez, señalar que, en el presente trabajo se interrelacionan el método especulativo y el hipotético-deductivo, puesto que se trata de un artículo jurídico, ambiental y social.

\section{ASPECTOS DIACRÓNICOS EN LOS INSTRUMENTOS ECONÓMICOS DE LAS LEYES DEL SUELO DE 1956, 2008 Y 2015}

En las últimas décadas, España ha vivido lo que Font Arellano (2006) denomina la "explosión de la ciudad". Esta "explosión" viene marcada por la dispersión por el territorio de zonas residenciales, de actividades económicas secundarias y terciaras, por el flujo de personas y mercancías, que demandan y disponen nuevos usos del suelo; y que, a posteriori, definen y marcan nuevas morfologías espaciales que se traducen en nuevos modelos de "creación de ciudad". Estas transformaciones territoriales han

8 En el TRLS 2/2008 se afirma que "hoy parece asimismo claro que el urbanismo debe responder a los requerimientos de un desarrollo sostenible, minimizando el impacto de aquel crecimiento y apostando por la regeneración de la ciudad existente". 
sido consecuencia directa del incremento de la población en áreas cada vez más alejadas de los núcleos urbanos, favoreciendo la "densificación" de zonas urbanas dispersas, lo que ha propiciado un proceso de descentralización económica y política. De este modo, se ha generalizado la difusión de actividades productivas terciarias e industriales en las periferias de las ciudades, se ha incrementado el flujo de personas y mercancías -como consecuencia de la descentralización entre empleo, servicios y residencia-, han favorecido el surgimiento de nuevos cetros de terciario y incidiendo, directa e indirectamente, en nuevas centralidades urbanos -normalmente, localizados en los bordes de granes vías de comunicación-, entre otros. Y, como consecuencia principal de dichos cambios o transformaciones territoriales, los nuevos centros urbanos están definidos y orientados por la capacidad de dirección de la economía, de la información, de las comunicaciones y del conocimiento con lo que, lejos de ser dependientes, lo que hacen es crear nuevas centralidades a la par que nuevas necesidades; todo ello sin olvidarnos de la perdida de espacios naturales, la desprotección del medio ambiente y la falta de conservación de la naturaleza. En definitiva, nos encontramos ante nuevas formas de hacer ciudad en las que la especialización espacial, la recalificación urbana, la dispersión en el territorio o la reorganización productiva han creado y crean nuevas formas de vida urbana y de los instrumentos de planeamiento e intervención en el territorio. Con todo ello, como instrumento de planeamiento destaca la presente Ley del Suelo 2/2008, que tiene como objeto la optimización de la prestación de servicios, la protección ambiental, la colaboración interinstitucional y el establecimiento ${ }^{9}$ de instrumentos de mejora de la competencia de las administraciones y los gobiernos locales con el fin de optimizar el acceso, el uso y el disfrute de los servicios-tanto públicos como privados-. De este modo, instrumentos de planificación como el que hemos llevado a estudio, tienen como fin -o así debería ser-, la optimización y el uso eficiente del recurso suelo ${ }^{10}$, mediante una optima estructuración y reestructuración del urbanismo, con la correcta dotación y creación de infraestructuras -fundamentalmente de transporte y comunicación- que eliminen las costosas congestiones -en términos económicos y ecológicos-, redes telemáticas para el flujo de informaciones y conocimientos, nuevas formas urbanas que hagan posible la existencia del transporte colectivo, el uso más racional de recursos naturales

9 TRLS 2/2008, Artículo 2. Principio de desarrollo territorial y urbano sostenible.

1. Las políticas públicas relativas a la regulación, ordenación, ocupación, transformación y uso del suelo tienen como fin común la utilización de este recurso conforme al interés general y según el principio de desarrollo sostenible, sin perjuicio de los fines específicos que les atribuyan las Leyes.

2. En virtud del principio de desarrollo sostenible, las políticas a que se refiere el apartado anterior deben propiciar el uso racional de los recursos naturales armonizando los requerimientos de la economía, el empleo, la cohesión social, la igualdad de trato y de oportunidades, la salud y la seguridad de las personas y la protección del medio ambiente, contribuyendo en particular a:

a) La eficacia de las medidas de conservación y mejora de la naturaleza, la flora y la fauna y de la protección del patrimonio cultural y del paisaje.

b) La protección, adecuada a su carácter, del medio rural y la preservación de los valores del suelo innecesario o inidóneo para atender las necesidades de transformación urbanística.

c) La prevención adecuada de riesgos y peligros para la seguridad y la salud públicas y la eliminación efectiva de las perturbaciones de ambas.

d) La prevención y minimización, en la mayor medida posible, de la contaminación del aire, el agua, el suelo y el subsuelo.

3. Además de lo dispuesto en el apartado anterior, los poderes públicos propiciarán la consecución de un medio urbano que esté suficientemente dotado, en el que se ocupe el suelo de manera eficiente, y en el que se combinen los usos de forma funcional, garantizando, en particular:

a) La movilidad en coste y tiempo razonable, sobre la base de un adecuado equilibrio entre todos los sistemas de transporte, que, no obstante, otorgue preferencia al transporte público y colectivo y potencie los desplazamientos peatonales y en bicicleta.

b) La accesibilidad universal, de acuerdo con los requerimientos legales mínimos, de los edificios de uso privado y público, de los espacios de uso público y de los transportes públicos.

c) El uso eficiente de los recursos y de la energía, preferentemente de generación propia, así como la introducción de energías renovables. d) La prevención y, en todo caso, la minimización en la mayor medida posible, por aplicación de todos los sistemas y procedimientos legalmente previstos, de los impactos negativos de los residuos urbanos y de la contaminación acústica.

La persecución de estos fines se adaptará a las peculiaridades que resulten del modelo territorial adoptado en cada caso por los poderes públicos competentes en materia de ordenación territorial y urbanística.

4. Los poderes públicos promoverán las condiciones para que los derechos y deberes de los ciudadanos establecidos en los artículos siguientes sean reales y efectivos, adoptando las medidas de ordenación territorial y urbanística que procedan para asegurar un resultado equilibrado, favoreciendo o conteniendo, según proceda, los procesos de ocupación y transformación del suelo.

El suelo vinculado a un uso residencial por la ordenación territorial y urbanística está al servicio de la efectividad del derecho a disfrutar de una vivienda digna y adecuada, en los términos que disponga la legislación en la materia.

10 TRLS 2/2008, artículo 4. Derechos del ciudadano.

Todos los ciudadanos tienen derecho a:

a) Disfrutar de una vivienda digna, adecuada y accesible, concebida con arreglo al principio de diseño para todas las personas, que constituya su domicilio libre de ruido u otras inmisiones contaminantes de cualquier tipo que superen los límites máximos admitidos por la legislación aplicable y en un medio ambiente y un paisaje adecuados. 
escasos (Mella Márquez, 2008) -por parte de las instituciones y de los ciudadanos ${ }^{11}$-, la localización de actividades productivas y la instalación de los equipamientos ambientales necesarios para el uso eficiente de los recursos hídricos y que permitan la correcta eliminación de residuos. Puesto que, como afirma Méndez Rexach (2014) hoy día, la regeneración urbana no es una opción política a la transformación del suelo rural mediante obras de urbanización, sino una exigencia del principio de desarrollo territorial y urbano sostenible ${ }^{12}$, tal y como se recoge en el Texto Refundido la Ley del Suelo 7/2015, e implícito en la Constitución ${ }^{13}$. La citada Ley establece que las políticas urbanas se deben basar en la regeneración y mejora de los tejidos existentes y no en nuevas ocupaciones de suelo. En la propia Ley el concepto de actuaciones de urbanización comprende tanto las actuaciones de reforma o renovación del suelo ya urbanizado como las de primera transformación del suelo rural, si bien estas últimas en lo sucesivo deberían ser, si no excepcionales, sí, el menos, suficientemente justificadas. Como señala el preámbulo de la citada Ley "el crecimiento urbano sigue siendo necesario, pero hoy parece asimismo claro que el urbanismo debe responder a los requerimientos de un desarrollo sostenible, minimizando el impacto de aquel crecimiento y apostando por la regeneración de la ciudad existente" (TRLS 2/2008).

A tenor de todo lo expuesto, se hace imprescindible realizar un estudio pormenorizado de la estrecha vinculación existente entre la Ley del Suelo y el Medio Ambiente, ahondando, posteriormente, en la instrumentación económica recogida en la misma, con el fin de prevenir, proteger, conservar y restaurar un recurso natural de gran valor como es el suelo, en nuestro país.

\subsection{Desarrollo, medio ambiente y territorio en el Real Decreto Legislativo 2/2008 y trasposición al Real Decreto legislativo 7/2015.}

Uno de los puntos principales del Texto Refundido de la Ley del Suelo 2/2008, no existente en las leyes del suelo anteriores, es la incorporación de las nuevas bases ambientales de sostenibilidad en la ordenación y utilización del suelo, establecidas por la política de la Unión Europea. De hecho, en la "Exposición de Motivos" de la presente Ley se hace regencia a la Comunicación de la Comisión Europea sobre una Estrategia Temática para el Medio Ambiente Urbano en la que se propone:

un modelo de ciudad compacta y advierte de los graves inconvenientes de la urbanización dispersa o desordenada: impacto ambiental, segregación social e ineficiencia económica por los elevados costes energéticos, de construcción y mantenimiento de infraestructuras y de prestación de los servicios públicos. El suelo, además de un recurso económico, es también un recurso natural, escaso y no renovable (TRLS 2/2008).

Si bien, debemos señalar que en materia de instrumentación económica en materia de gestión ambiental, la Ley carece casi por completo de competencia ${ }^{14}$; lo que limita las capacidades de actuación,

11 TRLS 2/2008, artículo 5. Deberes del ciudadano.

Todos los ciudadanos tienen el deber de:

a) Respetar y contribuir a preservar el medio ambiente y el paisaje natural absteniéndose de realizar actuaciones que contaminen el aire, el agua, el suelo y el subsuelo o no permitidas por la legislación en la materia.

b) Cumplir los requisitos y condiciones a que la legislación sujete las actividades molestas, insalubres, nocivas y peligrosas, así como emplear en ellas en cada momento las mejores técnicas disponibles conforme a la normativa aplicable, encaminadas a eliminar o reducir los efectos negativos señalados.

c) Respetar y hacer un uso racional y adecuado, acorde en todo caso con sus características, función y capacidad de servicio, de los bienes de dominio público y de las infraestructuras y los servicios urbanos.

d) Respetar y contribuir a preservar el paisaje urbano y el patrimonio arquitectónico y cultural absteniéndose en todo caso de realizar cualquier acto o desarrollar cualquier actividad no permitidos.

12 Resulta de interés la consulta de los siguientes trabajos, a saber: Sotelo Navalpotro, (1999); Sotelo Navalpotro, Sotelo Pérez y García, (2013).

13 Constitución Española, artículo 45:

1. Todos tienen el derecho a disfrutar de un medio ambiente adecuado para el desarrollo de la persona, así como el deber de conservarlo.

2. Los poderes públicos velarán por la utilización racional de todos los recursos naturales, con el fin de proteger y mejorar la calidad de la vida y defender y restaurar el medio ambiente, apoyándose en la indispensable solidaridad colectiva.

Constitución Española, artículo 46: Los poderes públicos garantizarán la conservación y promoverán el enriquecimiento del patrimonio histórico, cultural y artístico de los pueblos de España y de los bienes que lo integran, cualquiera que sea su régimen jurídico y su titularidad. La ley penal sancionará los atentados contra este patrimonio.

14 TSLS 2/2008. Exposición de Motivos:

Pero además, del nuevo orden competencial instaurado por el bloque de la constitucionalidad, según ha sido interpretado por la doctrina del Tribunal Constitucional, resulta que a las Comunidades Autónomas les corresponde diseñar y desarrollar sus propias políticas en materia urbanística. Al Estado le corresponde a su vez ejercer ciertas competencias que inciden sobre la materia, pero debiendo evitar condicionarla en lo posible. 
provocando así que las buenas praxis recogidas en la "Exposición de Motivos" y en el "Título Preliminar" de dicha Ley quede limitadas, o condicionadas, por otras legislaciones. A pesar todo, la Ley aporta una serie de propuestas concretas y concisas sobre la actuación en la conservación y preservación -que no en la regeneración- del medio natural y, por ende, del suelo, sobre el que se asientan tanto los edificios e infraestructuras como las actividades socioeconómicas de la población. Con todo ello, es necesario realizar un análisis pormenorizado de la relevancia que cobra el Medio Ambiente en la Ley del Suelo española. Ya en la "Exposición de Motivos" se parte de la idea fundamental de la importancia que cobra la protección de la naturaleza en la propia Constitución Española, señalando que;

La Constitución de 1978 establece un nuevo marco de referencia para la materia, tanto en lo dogmático como en lo organizativo. La Constitución se ocupa de la regulación de los usos del suelo en su artículo 47, a propósito de la efectividad del derecho a la vivienda y dentro del bloque normativo ambiental formado por sus artículos 45 a 47 , de donde cabe inferir que las diversas competencias concurrentes en la materia deben contribuir de manera leal a la política de utilización racional de los recursos naturales y culturales, en particular el territorio, el suelo y el patrimonio urbano y arquitectónico, que son el soporte, objeto y escenario necesario de aquéllas al servicio de la calidad de vida (TRLS 2/2008).

De igual modo, un punto fundamental recogido en la "Exposición de Motivos" en materia ambiental, es la vinculación existente la ciudadanía y el propio "suelo", incluyen los "derechos y deberes de orden socio-económico y medioambiental de toda persona con independencia de cuales sean su actividad o patrimonio" (TRLS 2/2008):

Primero, el de la ciudadanía en general en relación con el suelo y la vivienda, que incluye derechos y deberes de orden socio-económico y medioambiental de toda persona con independencia de cuáles sean su actividad o su patrimonio, es decir, en el entendimiento de la ciudadanía como un estatuto de la persona que asegure su disfrute en libertad del medio en el que vive, su participación en la organización de dicho medio y su acceso igualitario a las dotaciones, servicios y espacios colectivos que demandan la calidad y cohesión del mismo (TRLS 2/2008).

Uno de los puntos más relevantes, referentes al establecimiento de las bases económicas y medioambientales de la presente Ley la encontramos en el "Título Preliminar". Ya en el artículo 1, en el que se inscribe el objeto de la presente Ley se estipula que:

Esta Ley regula las condiciones básicas que garantizan la igualdad en el ejercicio de los derechos y en el cumplimiento de los deberes constitucionales relacionados con el suelo en todo el territorio estatal. Asimismo, establece las bases económicas y medioambientales de su régimen jurídico, su valoración y la responsabilidad patrimonial de las Administraciones Públicas en la materia (TRLS 2/2008).

Y, en el art. 215, se especifica el "principio de desarrollo territorial y urbano sostenible" sobre el que se asientan las políticas regulatorias que favorezcan el uso racional de los recursos naturales:

1. Las políticas públicas relativas a la regulación, ordenación, ocupación, transformación y uso del suelo tienen como fin común la utilización de este recurso conforme al interés general y según el principio de desarrollo sostenible, sin perjuicio de los fines específicos que les atribuyan las Leyes.

2. En virtud del principio de desarrollo sostenible, las políticas a que se refiere el apartado anterior deben propiciar el uso racional de los recursos naturales armonizando los requerimientos de la economía, el empleo, la cohesión social, la igualdad de trato y de oportunidades, la salud y la seguridad de las personas y la protección del medio ambiente, contribuyendo en particular a:

a) La eficacia de las medidas de conservación y mejora de la naturaleza, la flora y la fauna y de la protección del patrimonio cultural y del paisaje.

b) La protección, adecuada a su carácter, del medio rural y la preservación de los valores del suelo innecesario o inidóneo para atender las necesidades de transformación urbanística.

c) La prevención adecuada de riesgos y peligros para la seguridad y la salud públicas y la eliminación efectiva de las perturbaciones de ambas.

d) La prevención y minimización, en la mayor medida posible, de la contaminación del aire, el agua, el suelo y el subsuelo.

15 Traspuesto al TRLS7/2015, en el Artículo 3: "Principios de desarrollo territorial y urbano sostenible. 
3. Además de lo dispuesto en el apartado anterior, los poderes públicos propiciarán la consecución de un medio urbano que esté suficientemente dotado, en el que se ocupe el suelo de manera eficiente, y en el que se combinen los usos de forma funcional, garantizando, en particular:

a) La movilidad en coste y tiempo razonable, sobre la base de un adecuado equilibrio entre todos los sistemas de transporte, que, no obstante, otorgue preferencia al transporte público y colectivo y potencie los desplazamientos peatonales y en bicicleta.

b) La accesibilidad universal, de acuerdo con los requerimientos legales mínimos, de los edificios de uso privado y público, de los espacios de uso público y de los transportes públicos.

c) El uso eficiente de los recursos y de la energía, preferentemente de generación propia, así como la introducción de energías renovables.

d) La prevención y, en todo caso, la minimización en la mayor medida posible, por aplicación de todos los sistemas y procedimientos legalmente previstos, de los impactos negativos de los residuos urbanos y de la contaminación acústica.

La persecución de estos fines se adaptará a las peculiaridades que resulten del modelo territorial adoptado en cada caso por los poderes públicos competentes en materia de ordenación territorial y urbanística.

4. Los poderes públicos promoverán las condiciones para que los derechos y deberes de los ciudadanos establecidos en los artículos siguientes sean reales y efectivos, adoptando las medidas de ordenación territorial y urbanística que procedan para asegurar un resultado equilibrado, favoreciendo o conteniendo, según proceda, los procesos de ocupación y transformación del suelo.

El suelo vinculado a un uso residencial por la ordenación territorial y urbanística está al servicio de la efectividad del derecho a disfrutar de una vivienda digna y adecuada, en los términos que disponga la legislación en la materia (TRLS 2/2008).

Desde el punto de vista de la "Exposición de Motivos" y del "Título Preliminar" parece que la Ley supone, en el apartado que se comenta en este artículo, un avance evidente importante respecto a planteamientos anteriores.

En cuanto al "Título Primero", cabe destacar una cuestión fundamental como son los derechos de los ciudadanos. En el art.4 se expone ${ }^{16}$;

Todos los ciudadanos tienen derecho a:

a) Disfrutar de una vivienda digna, adecuada y accesible, concebida con arreglo al principio de diseño para todas las personas, que constituya su domicilio libre de ruido $u$ otras inmisiones contaminantes de cualquier tipo que superen los límites máximos admitidos por la legislación aplicable y en un medio ambiente y un paisaje adecuados (TRLS 2/2008).

A partir de este momento la práctica totalidad de las referencias lo van a ser a otro tipo de legislación (básicamente la legislación sectorial) y la Ley se convierte, fundamentalmente, en un recordatorio de la necesidad de cumplir toda la legislación ambiental. En el caso del artículo anterior las leyes del ruido estatal y autonómicas y toda la legislación que se refiere a la inmisión de contaminantes,... Por ello, en el art. 5 de la presente Ley se hace alusión, a los deberes de los ciudadanos y a la necesidad del cumplimiento de la normativa ambiental, con independencia de la concienciación ciudadana ${ }^{17}$.

Todos los ciudadanos tienen el deber de:

a) "Respetar y contribuir a preservar el medio ambiente y el paisaje natural absteniéndose de realizar actuaciones que contaminen el aire, el agua, el suelo y el subsuelo o no permitidas por la legislación en la materia" (TRLS 2/2008).

A su vez, dentro de este "Título Primero", en el art.9 se hace hincapié en la educación ambiental y en la formación de la sociedad en materia ambiental, desde la legislación:

En el suelo que sea rural a los efectos de esta Ley, o esté vacante de edificación, el deber de conservado supone mantener los terrenos y su masa vegetal en condiciones de evitar riesgos de erosión, incendio, inundación, para la seguridad o salud públicas, daño o perjuicio a terceros o al interés general, incluido el ambiental; prevenir la contaminación del suelo, el agua o el aire y las inmisiones contami-

16 Traspuesto al TRLS7/2015, en su Artículo 5: "Derechos del ciudadano". 17 Traspuesto al TRLS7/2015, en su Artículo 6: "Deberes del ciudadano". 
nantes indebidas en otros bienes y, en su caso, recuperados de ellas; y mantener el establecimiento y funcionamiento de los servicios derivados de los usos y las actividades que se desarrollen en el suelo (TRLS 2/2008).

Por lo tanto, ya no es cuestión de buenas intenciones, sino de obligaciones específicas que han de cumplir los ciudadanos. Ya sea mediante la prevención de la contaminación como la conservación y preservación de la sostenibilidad ambiental del planeta. Por ello, tal vez este es uno de los artículos de dicha Ley, más relevantes en materia medioambiental.

Posteriormente, ya en el "Título segundo" se recoge uno de los ejes estructurales de la presente Ley, con su correspondiente complejidad y polémica, puesto que aborda la temática de los "criterios básicos de utilización del suelo" -fundamentales para el bueno uso y puesta en práctica de dichas medidas de protección ambiental. En el art. $10^{18}$ de la presente Ley del Suelo 2/2008 ${ }^{19}$ se recogen las bases para hacer efectivos los principios, derechos y deberes de los ciudadanos, por ello, en dicho artículo se establece que:

c) Atender, en la ordenación que hagan de los usos del suelo, a los principios de accesibilidad universal, de igualdad de trato y de oportunidades entre mujeres y hombres, de movilidad, de eficiencia energética, de garantía de suministro de agua, de prevención de riesgos naturales y de accidentes graves, de prevención y protección contra la contaminación y limitación de sus consecuencias para la salud o el medio ambiente.

2. Las instalaciones, construcciones y edificaciones habrán de adaptarse, en lo básico, al ambiente en que estuvieran situadas, y a tal efecto, en los lugares de paisaje abierto y natural, sea rural o marítimo, o en las perspectivas que ofrezcan los conjuntos urbanos de características histórico-artísticas, típicos o tradicionales, y en las inmediaciones de las carreteras y caminos de trayecto pintoresco, no se permitirá que la situación, masa, altura de los edificios, muros y cierres, o la instalación de otros elementos, limite el campo visual para contemplar las bellezas naturales, rompa la armonía del paisaje o desfigure la perspectiva propia del mismo (TRLS 2/2008).

Otro de los ejes fundamentales de la presente Ley en materia medioambiental, lo encontramos en el artículo $15^{20}$, dedicado a la "Evaluación y seguimiento de la sostenibilidad del desarrollo urbano" ${ }^{21}$ :

1. Los instrumentos de ordenación territorial y urbanística están sometidos a evaluación ambiental de conformidad con lo previsto en la legislación de evaluación de los efectos de determinados planes y programas en el medio ambiente y en este artículo, sin perjuicio de la evaluación de impacto ambiental de los proyectos que se requieran para su ejecución, en su caso.

2. El informe de sostenibilidad ambiental de los instrumentos de ordenación de actuaciones de urbanización deberá incluir un mapa de riesgos naturales del ámbito objeto de ordenación.

Los informes a que se refiere este apartado serán determinantes para el contenido de la memoria ambiental, que solo podrá disentir de ellos de forma expresamente motivada.

5. Las Administraciones competentes en materia de ordenación y ejecución urbanísticas deberán elevar al órgano que corresponda de entre sus órganos colegiados de gobierno que deberá considerar al menos la sostenibilidad ambiental y económica a que se refiere este artículo.

6. La legislación sobre ordenación territorial y urbanística establecerá en qué casos el impacto de una actuación de urbanización obliga a ejercer de forma plena la potestad de ordenación del municipio o del ámbito territorial superior en que se integre, por trascender del concreto ámbito de la actuación los efectos significativos que genera la misma en el medio ambiente (TRLS 2/2008).

Por último, no por ello menos importante, cabe destacar que en el "Título Tercero", dedicado a valoraciones, se establecen las bases para la puesta en valor del recursos natural "suelo" atendiendo a las distintas tipologías de suelo recogidas en la presente Ley, tal y como veremos a continuación.

18 Traspuesto al TRLS7/2015, en su Artículo 20: "Criterios básicos de utilización del suelo".

19 Como afirma el profesor Fariñas Tojo (2007), "probablemente este artículo ayudará a un mejor control judicial de la discrecionalidad del planeamiento" (p. 298).

20 Traspuesto al TRLS7/2015, en el Artículo 22: "Evaluación y seguimiento de la sostenibilidad del desarrollo urbano, y garantía de la viabilidad técnica y económica de las actuaciones sobre el medio urbano".

21 Cuestión recogida y analizada en la Ley 9/2006 sobre la evaluación de los efectos de determinados planes y programas sobre el medio ambiente. 


\subsection{Evolución del concepto de "suelo"}

Uno de los puntos principales a la hora de realizar un estudio pormenorizado de la instrumentación económica de la Ley del Suelo y analizar su evolución desde que se aprobó la primera Ley del Suelo de 1956, parte de la descripción del concepto y tipología de suelo, en las distintas legislaciones.

De forma concreta en esta Ley, atendiendo a las distintas definiciones existentes de suelo, podríamos afirmar que, desde el punto de vista del urbanismo y la ordenación del territorio, el suelo es el espacio físico sobre el que se asientan edificaciones e infraestructuras, en el que el ser humano realiza y desarrolla sus actividades diarias, económicas y sociales. Así pues, la planificación territorial y la regulación urbanística determinan diferentes tipologías de suelo, atendiendo a las distintas iniciativas que se autoricen sobre su uso y disfrute, destacando así el suelo edificable, el suelo industrial, el suelo agrícola,... entre otros.

De este modo, el suelo es concebido como un recurso económico importante, sobre todo para el mercado de la vivienda y como determinante del valor de las inversiones. El propio concepto de "Suelo" en la Ley de 1956, presenta como característica más destacada, el hecho de que lo concibe como un recurso natural cuyo valor es meramente económico. diferenciándose y desglosándose diversos problemas que requieren solución, referentes al uso y disfrute del suelo, y que luego se han ido plasmando en las diferentes reformas recogidas en las Leyes posteriores del suelo, tal y como podemos observar en los parágrafos siguientes:

a) La retención de terrenos por propietarios que no urbanizan ni edifican ni acceden a enajenar sus terrenos para urbanizar y construir a precios de justa estimación. En la evaluación del suelo que circunda al núcleo urbano prepondera, en efecto, la tendencia de hacer actuar las expectativas de uso o rentas futuras que se incorporan así como valores adicionales al valor actual del fondo, se computa indebidamente la plusvalía que en su momento será el resultado principal de la inversión urbanizadora, sin tener en cuenta que en rigor debe estar ausente del calculo, puesto que cuando, efectivamente llegue a producirse, como consecuencia de las obras en proceso ha de revertir en gran parte en la comunidad, previa aplicación del tratamiento fiscal adecuado. Lo cierto es, sin embargo, que suelen pretenderse precios de especulación, en lugar de precios reales, y en tanto se consiguen o no se hace imposible demora la movilización de la propiedad territorial, es decir se impide la parcelación, venta y edificación de los solares resultantes y la saturación del mercado con ofertas de terrenos a precios razonables. El beneficio que puede obtenerse de transformar el terreno rustico en solar es perfectamente licito, siempre que sea el propietario quien haya costeado la urbanización determinante de aquella mejora y subsiguiente incremento de valor. Pero en cambio, la caprichosa elevación del precio cuando todavía no se ha urbanizado ni desembolsado por los propietarios el coste de las obras correspondientes, implica usurpación de algo no perteneciente al dueño que repercute en perjuicio de la comunidad.

b) La imposibilidad de disponer de terrenos amplios para destinarlos a espacios libres en interés del embellecimiento y de las condiciones sanitarias de los núcleos urbanos.

c) La falta de distribución equitativa del aumento del valor del suelo, que debe ser afectado, en primer lugar, a amortizar los terrenos necesarios para las vías y espacios libres; en segundo termino, al pago de las obras de urbanización y por ultimo atribuido justamente a los propietarios, de suerte que desaparezcan en lo posible las desigualdades actuales derivadas de conceder la edificación intensiva a unos mientras se niega o limita excesivamente a otros (LS56).

Por otra parte, puede destacarse que, se presentaban distintas tipologías de suelo. Así, en el titulo segundo, se detallaba la calificación urbanística, en la que se recogía la división que el Plan de Ordenación hacia del suelo de los municipios ${ }^{22}$, y clasificaba el territorio de los municipios en tres tipos de suelo: Urbano, Rústico y Reserva urbana. Respecto del "suelo urbano", también denominado "suelo usado" comprendía todos y cada uno de los terrenos que se incluían en el perímetro del casco, tal y como se recogen en el art. 63 de la LS56,

22 Además, según exponía el artículo 71 de la presente Ley, es la que confiera a los derechos y deberes a la propiedad a través de esta división de suelos. Artículo 71: La enajenación de fincas no modificará la situación de su titular en orden a las limitaciones y deberes instituidos por esta Ley o impuestos, en virtud de la misma, por los actos de ejecución de sus preceptos y el adquirente quedará subrogado en el lugar y puesto del anterior propietario en los compromisos que hubiere contraído con las Corporaciones públicas respecto a la urbanización y edificación. 
1. Constituirán el suelo urbano estos terrenos:

a) Los comprendidos en el perímetro que defina el casco de la población, conforme al artículo doce;

b) Los que estén urbanizados; y

c) Los que, aún sin urbanizar, se hallaren enclavados en sectores para los que ya existiere aprobado Plan parcial de ordenación.

2. Los terrenos de suelo urbano se clasificarán, según su destino en la ordenación, en las siguientes modalidades:

a) Viales, dedicados a calles y plazas;

b) Parques y jardines;

c) De edificación pública: y

d) De edificación privada.

3. A los efectos de esta Ley tendrán la calificación de solares las superficies de suelo urbano aptas para la edificación y urbanizadas con arreglo a las normas mínimas establecidas en cada caso por el Plan, y si éste no las concretare, se precisará que la vía a que la parcela de frente tenga pavimentada la calzada, encintado de aceras y disponga de los servicios de suministro de agua, desagües y alumbrado público (LS56).

De igual modo, se delimitaba lo que era el perímetro del casco establecido por el Plan General y como única limitación figuraba el no poder ser edificado si no se cumplían las condiciones de solar, y en tal caso deberá edificar los solares, bajo la carga de expropiación (Matesanz Parellada, 2009). Y, tal y como se recoge en el art.114 de la LS56, como único deber, la cesión de terrenos para viales, parques y jardines y los costes de la urbanización como pago "justo" a los beneficios obtenidos de ella.

El "suelo rústico", por su parte, también denominado "suelo sin usar", estaba definido como el "suelo que sobra", ya que no se podía incluir dentro del "suelo urbano", ni como "reserva urbana", recogiéndose su acepción en el art.65 de la LS56:

1. Con los mismos requisitos señalados en el artículo anterior y los demás que se previenen en el presente, también podrán enajenarse directamente terrenos para edificar viviendas a los peticionarios siguientes:

a) Entidades de carácter benéfico y social dedicadas a la construcción de casas económicas o de renta limitada;

b) Personas económicamente débiles, para su acceso a la pequeña propiedad, en operaciones de conjunto aprobadas por la Comisión Central de Urbanismo, a iniciativa propia, de las Corporaciones locales o del Instituto Nacional de la Vivienda.

2. Dentro de ese plazo, las personas a quienes interesare adquirir parcelas dirigirán sus solicitudes al Ayuntamiento, con los documentos justificativos de su situación familiar y económica (LS56).

Esta es una cuestión que pensamos es de gran importancia, ya que podemos afirmar que esta tipología, de notable interés a la hora de tratar de la Ordenación del Territorio, se recogía en el Plan de Ordenación Urbana, donde se estipulaba que se debía delimitar el mismo perímetro urbano que en las normas sobre suelo urbano, y aunque dentro del suelo rústico se señalaba la necesidad de conservación de determinados suelos agrícolas y forestales, esta protección no suponía una categoría, pretendiéndose, más bien, que las reservas de suelo permitieran la escalonada expansión de los núcleos urbanos y evitara la especulación, que entre otras cosas sustraía prematuramente terrenos a la agricultura.

La tercera tipología era el "suelo de reserva urbana", también denominado "suelo para usar", que comprendía aquellos terrenos que el Plan recogiera para ser urbanizados, pero que no se incluían en el "suelo urbano", es decir, aquellos que se extienden entre el perímetro del casco y el perímetro urbano definido por el Plan General, siendo objeto de los proyectos y planes de extensión, no pudiéndose realizar en ellos un uso distinto al especificado por el Plan General.

Constituirán el suelo de reserva urbana los terrenos comprendidos en un Plan general de ordenación para ser urbanizados y no calificables de suelo urbano según el párrafo 1 del artículo 63 (Art. 64 LS56).

Cabe destacar que no se detalla en este caso al igual que en el anterior ningún tipo de estatuto o deber, a excepción de las obligatorias cesiones. Así, pues, llegados a este punto, podemos afirmar que como hemos podido observar en las distintas calificaciones de suelo y en el texto de dicha Ley, que el medio ambiente, la conservación de los recursos naturales y, especialmente, la protección del suelo, no eran 
factores que pudiéramos calificar de relevantes. De hecho, no hay especificación alguna al respecto en ninguna parte del mismo.

La segunda de las aproximaciones que haremos es al "Suelo" en el Texto Refundido de la Ley de 2008 -fenómeno que se mantiene intacto en el actual TRLSRH 7/2015-. A diferencia de la anterior, el suelo, además de "un recurso económico", es también un "recurso natural, escaso y no renovable". De este modo, todo suelo rural tiene un valor ecológico apreciado, por lo que la liberación y el uso del mismo no debe ser especulativo, ni de acumulación, sino racional, con el fin de atender o satisfacer las necesidades sociales y económicas de la sociedad de manera eficiente. Todo ello, sin olvidar, que también el suelo urbano ya construido tiene un valor ambiental propio, "como creación cultural colectiva que es objeto de una permanente recreación, por lo que sus características deben ser expresión de su naturaleza y su ordenación debe favorecer su rehabilitación y fomentar su uso" (preámbulo TRLS 2/2008).

En este caso concreto, la Ley diferencia también distintos tipos de suelo. A tenor de la las políticas europeas $^{23}$, orientadas a la protección y conservación del medio ambiente, la nueva Ley considera el suelo como "un recurso natural, escaso y renovable" (prólogo TRLS 2/2008). De igual modo, por primera vez desde la primigenia Ley del Suelo de 1956, se modifica la terminología, dejando de hablar de clases para referirse a situaciones básicas del suelo, que en el artículo 12 del TRLS08 expone hablando de suelo rural y de suelo urbanizado. Se elimina, al menos dentro de la clasificación, aunque no en su esencia, el suelo urbanizable. Se distinguen dos situaciones que únicamente dependen de si el suelo esta transformado o no. El primero de ellos es el "suelo urbanizado", también denominado "suelo para usar", y viene definido en el art. 12. $3^{24}$, como;

3. Se encuentra en la situación de suelo urbanizado el que, estando legalmente integrado en una malla urbana conformada por una red de viales, dotaciones y parcelas propia del núcleo o asentamiento de población del que forme parte, cumpla alguna de las siguientes condiciones:

a) Haber sido urbanizado en ejecución del correspondiente instrumento de ordenación.

b) Tener instaladas y operativas, conforme a lo establecido en la legislación urbanística aplicable, las infraestructuras y los servicios necesarios, mediante su conexión en red, para satisfacer la demanda de los usos y edificaciones existentes o previstos por la ordenación urbanística o poder llegar a contar con ellos sin otras obras que las de conexión con las instalaciones preexistentes. El hecho de que el suelo sea colindante con carreteras de circunvalación o con vías de comunicación interurbanas no comportará, por sí mismo, su consideración como suelo urbanizado.

c) Estar ocupado por la edificación, en el porcentaje de los espacios aptos para ella que determine la legislación de ordenación territorial o urbanística, según la ordenación propuesta por el instrumento de planificación correspondiente (TRLS 2/2008).

A su vez, en el art. 14 del TRLS 2/2008 se estipula que las posibles actuaciones en suelo urbanizado se llevarán a cabo mediante las denominadas "Actuaciones de Transformación Urbanística", si bien, en materia ambiental no se hace referencia ni a derechos ni deberes por parte de los propietarios -tan solo a la conservación, rehabilitación y mejora y cumplimiento de los plazos en la edificación, como se recoge en el art. 9 de la presente Ley-. Pese a todo, sí se hace referencia a la cesión de suelo para viales, zonas verdes y dotaciones, en la que se estipula la cesión de entre un 5 y un 15\% para la administración, el coste y ejecución de la urbanización y la garantía de realojo.

El segundo de los tipos es el "suelo rural" también denominado "suelo para usar y proteger", y está definido por la Ley en el art. 12. $2^{25}$, como;

2. Está en la situación de suelo rural:

a) En todo caso, el suelo preservado por la ordenación territorial y urbanística de su transformación mediante la urbanización, que deberá incluir, como mínimo, los terrenos excluidos

23 El crecimiento urbano sigue siendo necesario, pero hoy parece asimismo claro que el urbanismo debe responder a los requerimientos de un desarrollo sostenible, minimizando el impacto de aquel crecimiento y apostando por la regeneración de la ciudad existente. La Unión Europea insiste claramente en ello, por ejemplo en la Estrategia Territorial Europea o en la más reciente Comunicación de la Comisión sobre una Estrategia Temática para el Medio Ambiente Urbano, para lo que propone un modelo de ciudad compacta y advierte de los graves inconvenientes de la urbanización dispersa o desordenada: impacto ambiental, segregación social e ineficiencia económica por los elevados costes energéticos, de construcción y mantenimiento de infraestructuras y de prestación de los servicios públicos.

24 Traspuesto al TRLS7/2015, en su Artículo 21: "Situaciones básicas del suelo".

25 Traspuesto al TRLS7/2015, en su Artículo 21: "Situaciones básicas del suelo". 
de dicha transformación por la legislación de protección o policía del dominio público, de la naturaleza o del patrimonio cultural, los que deban quedar sujetos a tal protección conforme a la ordenación territorial y urbanística por los valores en ellos concurrentes, incluso los ecológicos, agrícolas, ganaderos, forestales y paisajísticos, así como aquéllos con riesgos naturales o tecnológicos, incluidos los de inundación o de otros accidentes graves, y cuantos otros prevea la legislación de ordenación territorial o urbanística.

b) El suelo para el que los instrumentos de ordenación territorial y urbanística prevean o permitan su paso a la situación de suelo urbanizado, hasta que termine la correspondiente actuación de urbanización, y cualquier otro que no reúna los requisitos a que se refiere el apartado siguiente (TRLS 2/2008).

De esta forma, querríamos destacar el hecho de que una de las características esenciales de esta Ley, rompiendo con todas las legislaciones anteriores, es que se expresa claramente la necesidad de reducir el suelo urbanizable. Con anterioridad, sobre todo en la primigenia Ley del Suelo se recogía entre sus líneas la necesidad de incrementar el suelo urbano o urbanizable, con el fin de reducir así su precio.

A su vez, una cuestión importante a tener en cuenta es la delegación o cesión por parte del Estado a las Comunidades Autónomas que, a través de sus instrumentos urbanísticos, regulen la transformación de suelo rural en urbanizado. Este es un punto a tener en cuenta, sobre todo a la hora de analizar los Instrumentos Económicos de la Ley del Suelo para la protección y conservación del Medio Ambiente, ya que, como veremos en el epígrafe siguiente, todos los tributos y demás instrumentos económicos son cedidos a las Comunidades Autónomas, a excepción el "precio"26.

\section{LOS INSTRUMENTOS ECONÓMICOS Y LA LEY DEL SUELO}

La reforma de la Ley del Suelo española se justifica por la necesidad de acometer, mediante nuevos instrumentos más eficaces, la problemática de la gestión del recurso suelo en España y hacer frente, desde una perspectiva no sólo cuantitativa, sino también cualitativa, a las nuevas exigencias que reclama en la actualidad la administración de los recursos naturales, en general, y del suelo, en particular.

Desde una perspectiva económica, la Ley recoge entre sus líneas, exclusivamente, la instrumentación reglada en materia de "Impuestos sobre Transmisiones Patrimoniales y Actos Jurídicos Documentados" y la de los "precios" del suelo vs. vivenda. Tal y como vimos anteriormente, el resto de instrumentos económicos están cedidos totalmente a las Comunidades Autónomas y, por ende, a sus legislaciones ${ }^{27}$.

De igual modo, antes de adentrarnos en el análisis de la legislación debemos tener en cuenta que la sensibilización por el medioambiente existente en la Ley, tal y como observamos en los epígrafes anteriores, no se hace realmente patente en los diversos instrumentos económicos utilizados en la legislación. Procedamos, pues, al análisis de los mismos.

El primero de los instrumentos a tratar es el "Impuesto sobre Transmisiones Patrimoniales y Actos Jurídicos Documentados". La referencia del presente impuesto en el Texto Refundido de la Ley del Suelo 7/2015, la encontramos en el art.23.7 de la misma. En ella se establece que:

7. Las transmisiones de terrenos a que den lugar las operaciones distributivas de beneficios y cargas por aportación de los propietarios incluidos en la actuación de transformación urbanística, o en vir-

26 TRLS 2/2008, art.6: La legislación sobre ordenación territorial y urbanística regulara:

a) El derecho de iniciativa, en ejercicio de la libre empresa, para la actividad de ejecución de la urbanización cuando esta no deba o no vaya a realizarse por la propia Administración competente. La habilitación a particulares para el desarrollo de esta actividad deberá atribuirse mediante procedimiento con publicidad y concurrencia y con criterios de adjudicación que salvaguarden una adecuada participación de la comunidad en las plusvalías derivadas de las actuaciones urbanísticas, en las condiciones dispuestas por la legislación aplicable, sin perjuicio de las peculiaridades o excepciones que esta prevea a favor de la iniciativa de los propietarios del suelo.

Otro de los cambios introducidos, esta vez en la gestión, y dentro de las posibilidades que ofrece la falta de competencias, proviene del intento de dinamizar la gestión privada, ya sea en la urbanización del suelo, en la que contempla la adjudicación de las actuaciones urbanizadoras mediante procedimientos de publicidad, como en la construcción, aunque lo remite directamente a las comunidades autónomas.

27 TSLS 2/2008. Exposición de Motivos:

"Pero además, del nuevo orden competencial instaurado por el bloque de la constitucionalidad, según ha sido interpretado por la doctrina del Tribunal Constitucional, resulta que a las Comunidades Autónomas les corresponde diseñar y desarrollar sus propias políticas en materia urbanística. Al Estado le corresponde a su vez ejercer ciertas competencias que inciden sobre la materia, pero debiendo evitar condicionarla en lo posible". 
tud de expropiación forzosa, y las adjudicaciones a favor de dichos propietarios en proporción a los terrenos aportados por los mismos, estarán exentas, con carácter permanente, si cumplen todos los requisitos urbanísticos, del Impuesto sobre Transmisiones Patrimoniales y Actos Jurídicos Documentados, y no tendrán la consideración de transmisiones de dominio a los efectos de la exacción del Impuesto sobre el Incremento del Valor de los Terrenos de Naturaleza Urbana (TRLS 7/2015).

En cuanto a los Impuestos sobre Transmisiones Patrimoniales y Actos Jurídicos Documentados (ITP y AJD), cabe destacar que uno de los principales problemas que emanaban de las anteriores Leyes del Suelo a la hora de su ejecución era la dispersión de la normativa reguladora de sus beneficios fiscales -más concretamente, respecto de las exenciones ${ }^{28}$ - Por ello, al analizar el presente epígrafe debemos tener en cuenta que, tal y como se recoge en el Texto Refundido del Impuesto sobre Transmisiones Patrimoniales y Actos Jurídicos Documentados -Real Decreto Legislativo 1/1993, de 24 de septiembre-, la problemática emana de dos cuestiones fundamentales; la primera de ella es el ámbito dentro del impuesto, ya que se creaba confusión a la hora de estipular si el impuesto afecta a las Transmisiones Patrimoniales Onerosas o solo a los Actos Jurídicos Documentados; la segunda cuestión, es el alcance las operaciones exentas, puesto que se entiende que beneficia las adjudicaciones y aportaciones propias de la actuación en una operación de reparcelación, pero no queda igual de claro respecto de las segregaciones, expropiaciones forzosas o las agrupaciones. Por ello, con lo estipulado en la presente Ley del Suelo, que ha asumido cambios relevantes en el presente artículo, se ha sustituido la mención de las juntas de compensación y reparación por una referencia a las "operaciones distributivas de beneficios y cargas". Con lo que la inclusión de la expropiación forzosa como adquisición con derecho a la exención y el sorprendente énfasis que se hace en el carácter "permanente" de la exención. Con lo que se hace imprescindible remarcar que estos tres cambios lo son si se compara con la redacción del Texto Refundido del Impuesto, pero si se compara con el artículo 159.4 del Real Decreto Legislativo 1/1992, de 26 de junio, por el que se aprueba el Texto Refundido de la Ley sobre el régimen del suelo y ordenación urbana (precepto expresamente declarado en vigor por la Ley 6/1998), lo único que se modifica es la ampliación del ámbito por encima del de juntas y reparcelaciones.

Sin lugar a dudas, tras lo anteriormente expuesto nos aproximamos al instrumento económico más importante recogido en la presente Ley del Suelo; nos estamos refiriendo al "precio" del suelo y de la vivienda. A tenor de las condiciones económicas acontecidas en los últimos lustros -anteriores y posteriores a la aprobación de la presente Ley-, se ha hecho más que necesario ahondar en modificaciones en dicha materia como consecuencia directa de la vinculación entre el encarecimiento del suelo y la escasez del mismo -real o no, tal y como vimos anteriormente-, y, de la relación entre el papel del suelo y el incremento de los precios de la vivienda. Ya en la Ley del Suelo 6/1998, se planteó el incremento de la oferta de suelo, por lo que es aquí cuando se definió el concepto de suelo urbanizable como residual, ya que, de ese modo, se apostaba por una liberalización del mercado del suelo, con el fin de generar un modelo desarrollista. Si bien, la modificación de la definición de suelo urbanizable no evitó el incremento del precio del suelo durante el último ciclo alcista que supuso que el suelo se revalorizara más que la vivienda, antes de la crisis inmobiliaria.

Con todo ello, y analizando dichos instrumentos desde la misma Ley, se pone de manifiesto que dicha legislación tiene como fin resolver la escasez de suelo mediante la gestión del mismo, en vez, a través de la expansión urbana como se estipulaba en legislaciones anteriores. Por lo tanto, el objetivo de la presente Ley no es la de incrementar la oferta de suelo urbanizable, sino la de incidir sobre el proceso de transformación de suelo en urbanizado. Interpretar las buenas expectativas que se generaban en la presente Ley, nos llevan a plantear una serie de ideas que se nos antojan fundamentales; a saber: los encargados de la gestión de la política urbanística reside en los Ayuntamientos: A tenor de lo acontecido en estos últimos años, esto genera grandes deficiencias por la falta de una gestión eficiente y eficaz; por otra parte, mientras que la normativa en materia económica es cedida a las Comunidades Autónomas, que son las encargadas de la redacción y estipulación de la normativa, lo que "grosso modo", genera desigualdades territoriales en el uso y disfrute del suelo, así como ineficiencia y falta de equidad en la recaudación

\footnotetext{
28 Como afirma Pérez Martínez (2009):

"lo peculiar de la exención es que ha ido siguiendo desde hace tres décadas una evolución paralela tanto en la norma tributaria como en la urbanística. Si a eso se añade que las redacciones no han sido idénticas y que el camino seguido por ambos sectores del ordenamiento está trufado de inconstitucionalidades, derogaciones y textos refundidos, el resultado es cualquier cosa menos claro" (p. 23).
} 
impositiva, la presente legislación tiene como fin la eliminación de los fallos de mercado en el sector urbanístico -especulación del suelo, información asimétrica-, lo que repercute o debería repercutir en los "precios" del suelo, y, por último, en el análisis de la presente Ley se echa en falta una vinculación entre la instrumentación económica y la conservación de la naturaleza (todo ello sin olvidarnos que uno de los puntos principales de la Ley del Suelo, la protección del Medio Ambiente, no está realmente vinculado a los "precios" del suelo).

A su vez, debemos destacar que, con el fin de cumplir con la Constitución en materia de acceso a una vivienda digna en un medio urbano adecuado, en la presente ley se pretende asentar las bases económicas del mercado del suelo bajo un marco jurídico estable, puesto que desde la primigenia Ley de 1956 hasta la actual Ley del 2015, se han llevado a cabo nueve modificaciones de la normativa estatal, con sus correspondientes adaptaciones por parte de las Comunidades Autónomas, lo que genera problemas en el correcto desarrollo de las mismas, como consecuencia de la incertidumbre y de la elevación de los costes de adaptación. No debemos olvidar que el suelo es un bien privado -de ahí los fallos de mercado-, pero también es un recurso de interés general por lo que está justificada una correcta regulación -sin caer en el intervencionismo.

Por otro lado, como vimos con anterioridad, se pretende apostar por un modelo de ciudad compacta, a través de la regulación del suelo. Esto supone un uso racional de los recursos naturales vs. culturales y, más concretamente, del suelo y del patrimonio urbano, tal y como se recoge en la presente Ley y en la Constitución Española. Con ello, la Ley pretende equilibrar el derecho a la propiedad con la libertad de empresa, en la actividad urbanizadora; todo esto supone incentivar a los propietarios del suelo para ejercer su actividad mediante la iniciativa privada y sin caer en la oposición a la iniciativa pública, con el fin de mitigar o eliminar la especulación - tal vez solo sean buenos propósitos, en vez de realidades.

De igual modo, debemos señalar como un "eje" fundamental en la presente Ley, con no pocas implicaciones en la Ordenación del Territorio, el ámbito de la valoración del suelo, ya que ésta se aplica conforme a su situación en el momento de la tasación, sin tener en cuenta las expectativas especulativas. Esto supone que el régimen de valoración está determinado por la naturaleza del suelo (como vimos con anterioridad, la Ley actual del suelo estipula la existencia de dos tipologías de suelo, el suelo urbanizado y el suelo rural) y el grado de ejecución, es decir, por su valor de mercado atendiendo a su situación "real".

Así, pues, con el fin último de establecer una visión general de la relación existente entre estos Instrumentos Económicos y la capacidad de estos de "internalizar" costes externos generados por un mal uso del recurso natural "suelo" -afectando de manera negativa al medio ambiente, en general, y, al suelo como bien escaso, en particular-, se hace más que necesario realizar un breve análisis a las condiciones económicas actuales del mercado del suelo, para poder comprender la realidad urbanística que ha de ser regulada y gestionada por la presente Ley del Suelo, analizando así su vinculación con la protección y conservación del medio ambiente en España.

\subsection{El mercado del Suelo en España}

Comprender lo anteriormente expuesto necesita, cuando menos, que nos aproximemos al denominado "mercado del suelo" en nuestro país. A la hora de estudiar el mercado del suelo, debemos analizar de manera concisa cuales son las características esenciales del suelo para que, de este modo, podamos comprender la interacción de los distintos agentes económicos y mejorar la vinculación entre la instrumentación económica y el medio ambiente, con el fin de mitigar los efectos negativos de la especulación y el mal uso del recuro "suelo". Tal y como se recoge en la Ley 2/2008, el suelo es un recurso económico, natural, escaso y no renovable, y, a su vez, es un recurso no sustituible, no homogéneo, no renovable, no reproducible e inmóvil; por lo que, desde una triple visión económica, ecológica y social -ejes fundamentales de la sostenibilidad-, el suelo es un bien productivo agrario -sector primario-, es un espacio sobre el que se asientan las actividades productivas de bienes y de servicios, las infraestructuras o residencias -sector secundario y terciario- y es un depósito de valor como bien de inversión -sector cuaternario-. A su vez, como bien económico, podemos afirmar que se trata de un bien privado puro ya que es excluible -en cuanto a su tenencia o su uso- y es rival. Amén de ser un bien normal, ya que con el aumento de las rentas se incrementan las demandas de suelo. 
Por lo que, a tenor de dichas condiciones, la teoría económica nos mostraría cómo a través de la competencia perfecta (ver figura 1), se podría maximizar el beneficio y el bienestar de los agentes económicos, maximizando la utilidad con cantidades y precios eficientes.

Figura 1. Competencia Perfecta: el mercado del suelo en la Ley

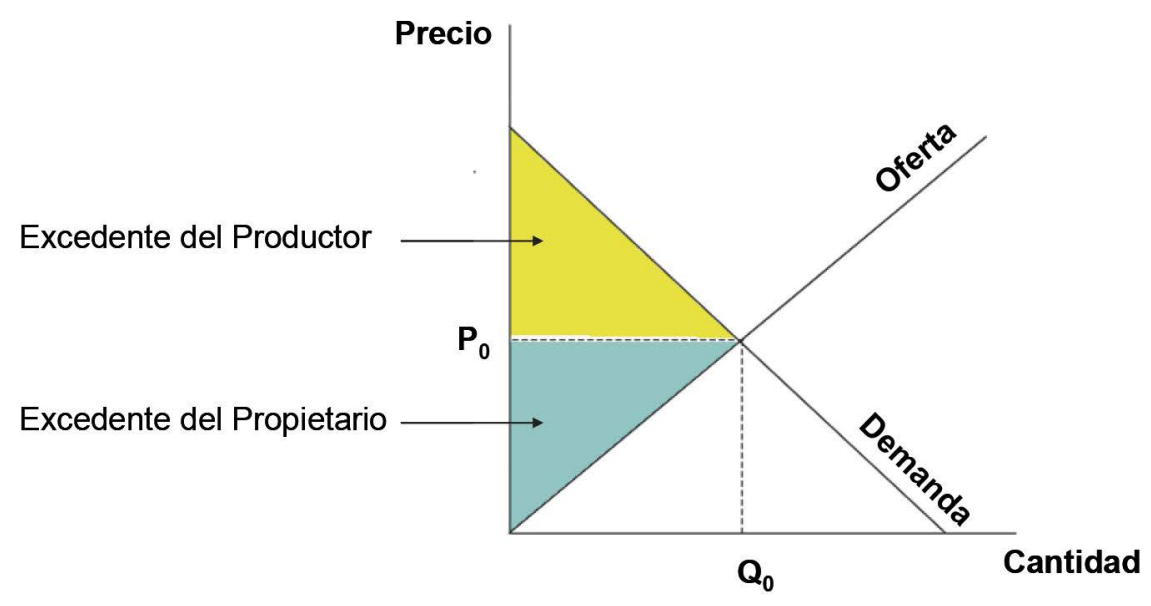

Fuente: Berges, A. y Ontiveros, E. (2007).

Si bien, como es sabido, el ideal de competencia perfecta no es factible ya que hay factores que justifican la intervención del sector público en el mercado del suelo, como consecuencia de los fallos de mercado ya mencionados, que hacen que éste no sea perfectamente competitivo, además de la existencia de costes de transacción, que inciden de forma directa en el hecho de que el precio no venga dado de antemano, y que para maximizar el bienestar social deba garantizarse la libre competencia de los agentes económicos (lógicamente, no debemos olvidarnos que la competencia perfecta no es compatible con la intervención pública y la libre interacción entre agentes). Esto nos lleva a colegir que las características del suelo ya descritas condicionan la capacidad de respuesta ante modificaciones en la demanda del suelo, si bien suele valorarse más la tendencia el comportamiento de la oferta en el mercado del suelo, por ello, no debemos olvidarnos de la demanda del mismo -la cual depende de múltiples factores como la localización en el territorio, la riqueza y la renta de las familias, la financiación del suelo,...-, cuestión fundamental, y hoy día prácticamente olvidada.

Del mismo modo, al considerar al suelo como un bien no homogéneo, no sustituible, no reproducible y no plenamente comerciable, dado su inmovilismo, encontramos uno de los primeros desajustes entre la oferta y la demanda que producen que el mercado del suelo no sea plenamente competitivo. A esto añadir que su dependencia con respecto al mercado de la vivienda es relativamente importante, por lo que el precio del suelo tiende a estar determinado por el precio de la vivienda. De igual modo, cabe destacar que los elevados costes de transacción, la incertidumbre existentes sobre todo tras la "burbuja inmobiliaria", y la necesidad de grandes inversiones iniciales en la actividad inmobiliaria propician la concentración del suelo en pocas manos, frente al modelo ideal consistente en que el suelo sea un elemento más de un proceso en el que muchos pequeños compradores o inversores, detentan su propiedad. Por último, las externalidades negativas ${ }^{29}$, vinculadas a las ineficiencias propias de la provisión de bienes públicos, generan fallos de mercado en los servicios públicos sobre todo de las áreas urbanas dispersas, de aquí la importancia que cobra en la actualidad la compactación de las áreas urbanas, con el fin de evitar desajustes entre oferta y demanda, que hacen imposible la existencia de un mercado plenamente competitivo en una economía abierta como la española.

29 "La ocupación en cinta (por ejemplo a lo largo de carreteras), ocupación leap frog (consistente en urbanizar zonas no contiguas para esperar a que suba el precio de las intermedias y urbanizarlas posteriormente) y el consiguiente aumento del coste de la provisión de infraestructuras que estos tipos de ocupación comportan. La liberalización del mercado del suelo se enfrenta con un sector que presenta importantes externalidades y donde, por tanto, la solución competitiva no es la más adecuada desde el punto de vista del bienestar de los ciudadanos" (Ministerio de Obras Públicas, Transportes y Medio Ambiente, 1996, p. 15). 


\subsection{La oferta y la demanda de suelo en España}

Tal y como hemos señalado anteriormente, no son pocos los estudiosos de estos temas, para quienes el problema de los elevados precios del suelo, emanaba de la falta de suelo urbanizable, sobre todo si aceptamos al idea de que el suelo es un bien escaso e inmóvil. Si bien, tras la "burbuja" inmobiliaria ha quedado demostrado que con restricciones de cantidad de suelo disponible, se genera una caída del precio del suelo en a largo plazo, cuestión que sin embargo, no se ha dado. Sin lugar a dudas, semejante aserto era coherente, sobre todo si tenemos en cuenta que el suelo es caro, por ello si la ordenación urbana no ha previsto suficiente suelo, será suficiente con que los planes califiquen más suelo para mantener los precios estables. Sin embargo, esto no es lo que se llevó acabo con las anteriores Leyes del Suelo, quedando demostrado que la eliminación de la "frontera urbanística" no era una condición suficiente para la contención de los precios.

Es por esto por lo que, debemos plantearnos el caso de una localidad en la que dicha "frontera" suponga una restricción a la oferta de suelo; en esta situación la salida al mercado de más suelo urbanizable sería al menos una condición necesaria para la estabilidad de los precios del suelo. Pese a todo, tal y como señalan Roca y Burns (1998), el precio del suelo se forma del centro a la periferia, y no de la periferia al centro, lo que implica que una mayor oferta de suelo menos atractivo no tiene ningún efecto sobre el mercado del suelo y, por tanto, la existencia de más suelo urbanizable no sería ni siquiera una condición necesaria para la contención del precio (García Montalvo, 2000). Igualmente, destacar que el proceso de formación del precio del suelo está ligado al precio de la vivienda, y a las expectativas sobre el mismo. Por este motivo, y dado que la "frontera" no es constante a lo largo del tiempo, el suelo más allá de la misma adquiere también una renta expectante, que se mantendrá incluso cuando se elimine la "frontera" (ver figura 2).

Figura 2. La oferta y la demanda de suelo, en el corto y largo plazo
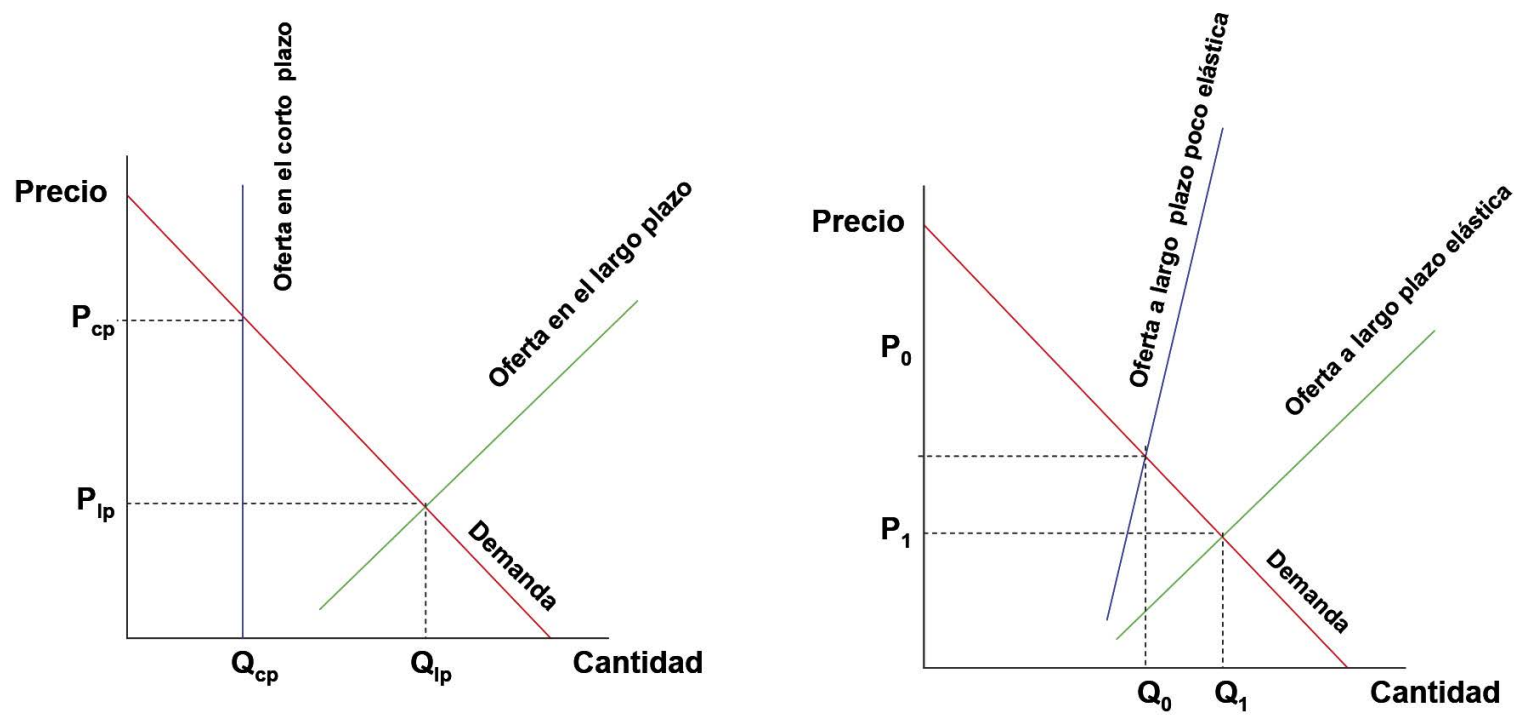

Fuente: Berges, A. y Ontiveros, E. (2007).

De los gráficos anteriores se deduce que cuando se produce un aumento de la demanda en el corto plazo, la oferta esta limitada (nos encontramos ante una oferta completamente inelástica, es decir, ante una variación en el precio del suelo, la cantidad ofertada sigue siendo la misma), por lo que podemos afirmar que es la demanda la que determina el precio, y no la oferta. Mientras que, en el largo plazo, ante un aumento de la demanda, la respuesta por parte de la oferta dependerá de la velocidad de gestión generada por parte de las Administraciones Públicas. Todo ello sin olvidarnos que existen costes de transacción que limitan o modifican la propia demanda y oferta de suelo. Como es bien sabido, los costes de transacción soportados en el proceso de urbanización son elevados y se concretan, fundamentalmente, en el pago de precios monopolísticos por la adquisición de últimas parcelas, por el riesgo asociado a la incertidumbre y por los elevados costes financieros de pagos iniciales de compra. De este modo, se incrementan los costes fijos del suelo fomentando la concentración de la propiedad, por lo que los beneficios obtenidos y la riqueza 
generada, recae en pocas manos, convirtiéndose en uno de los problemas que dimanan de la presente Ley del Suelo, al tener por objeto la concentración frente a la diseminación urbanística (ver Figura 3). Cobrando relativo interés el analizar los principales factores que inciden en la formación de los precios del suelo.

Figura 3. La oferta y la demanda de suelo con costes de transacción

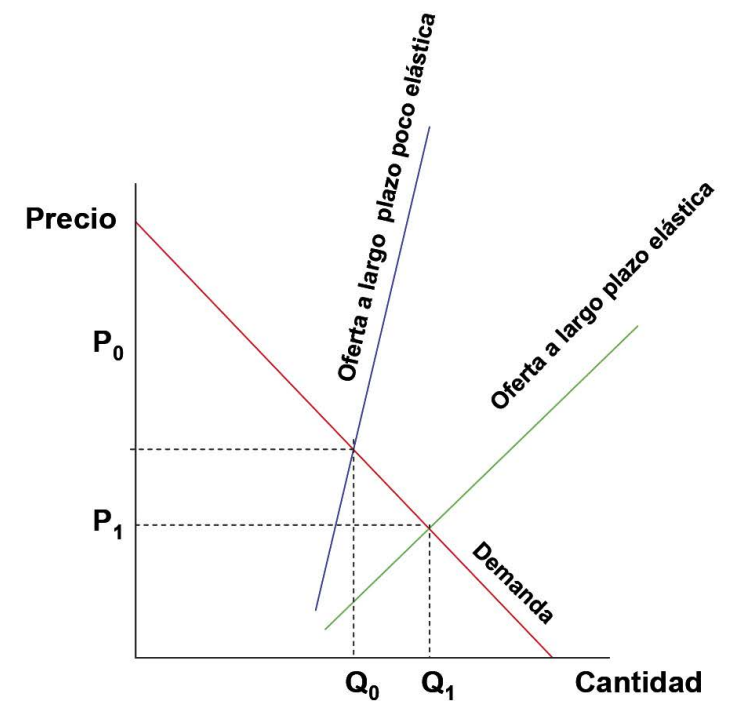

Fuente: Berges, A. y Ontiveros, E. (2007).

Destaca de esta forma, el hecho de que el suelo es un bien homogéneo, cuyo valor está determinado, fundamentalmente, por su localización, cuestión está de gran trascendencia territorial; de tal modo que, dependiendo de si nos encontramos en el centro o en la periferia urbana, los precios variarán (por lo que, en teoría, a mayor distancia del centro, menor precio), aunque en la última crisis urbanística generada por la "burbuja inmobiliaria", la disponibilidad de suelo urbanizado no se como una condición suficiente para la contención del mismo (Figura 4).

Figura 4. Mercado del suelo en el centro y en la periferia
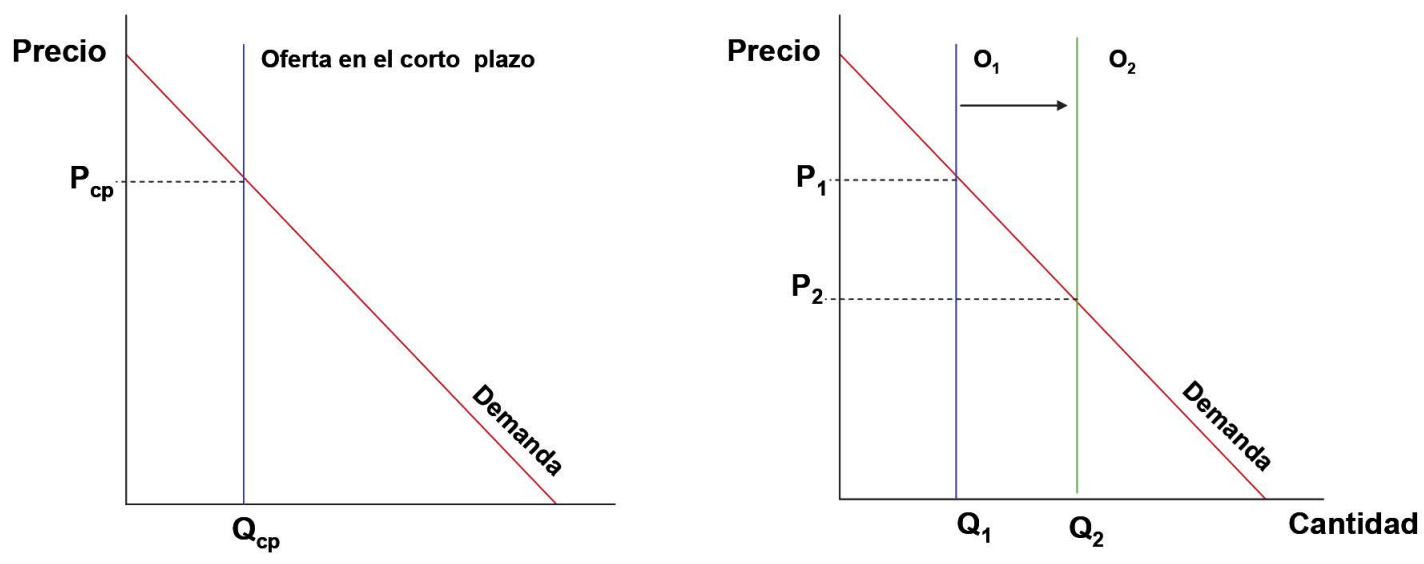

Fuente: Berges, A. y Ontiveros, E. (2007).

Otro factor a tener en cuenta es que, a través de la presente legislación, se estipula que el suelo es un factor productivo más en la construcción de viviendas, por lo que el precio de ambos está estrechamente relacionado. Algunos autores afirman que la demanda de suelo es una demanda derivada de vivienda, cuestión más que reseñable puesto que al adquirir una vivienda no solo compramos la vivienda en sí, sino que también adquirimos el suelo sobre el que se asienta, por lo que podemos afirmar que el precio del suelo está delimitado o marcado por las expectativas del mercado de vivienda. 
A tenor de los hechos acontecidos a partir del 2007 y 2008, años en los que se instauró la presente Ley del Suelo, y, como consecuencia del carácter cíclico del precio de la vivienda, íntimamente relacionado con procesos especulativos, que han marcado la evolución reciente de dicho sector económico, el precio del suelo se ve condicionado de forma determinante por dichos factores, pudiéndose afirmar que el precio del suelo está en función del precio de la vivienda, y viceversa, lo que genera un "círculo vicioso" de crecimiento de los precios que intensifica las fluctuaciones del ciclo económico. A esto añadir que el precio de la vivienda no solo está condicionado por el precio del suelo, sino que también viene marcado por otros factores exógenos como son los cambios en los saldos demográficos, el incremento de la riqueza personal o el incremento de la renta per cápita, las variaciones en los costes de construcción o las tasas de empleo. Todo ello sin olvidarnos de la influencia de la localización del suelo sobre el que se asientan dichas viviendas, incrementando el precio dada la inelasticidad de la oferta, en el corto plazo (ver figura 5).

Figura 5. Cambios en la demanda del suelo

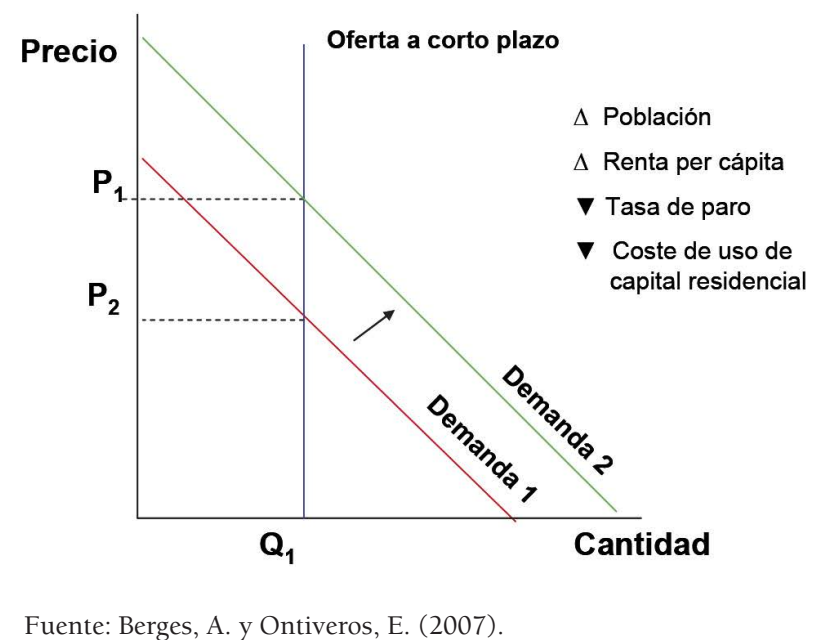

Llegados a este punto, podemos afirmar que la Ley del Suelo ha incorporado como una de sus ideas fundamentales la protección y la conservación del medio ambiente, si bien, entre los instrumentos económicos no cedidos a las Comunidades Autónomas, tan solo han quedado los ITP y AJD, y los precios del suelo, con lo que podemos afirmar que éstos no han llegado a conformarse como instrumentación primaria con la que desarrollar la actividad del sector de la construcción en pro de la conservación de la naturaleza (aunque podamos afirmar que conforman la estructura principal, en la búsqueda de la obtención de dichos fines). Poca cosa si tenemos en cuenta que los impactos económicos derivados de un desarrollo urbano expansivo suponían, antes de la aprobación de la presente Ley del Suelo, un consumo intensivo de un recurso escaso y no renovable como es el suelo. De este modo, amén de afectar a los costes de las viviendas unifamiliares construidas en la periferia, repercutían negativamente en el medio ambiente ya que se ejercía una mayor presión sobre el suelo en un territorio cada vez más amplio, encontrándonos ante una oportunidad perdida por mor de una no siempre bien calculada descentralización.

Es por esto por lo que se impone el evitar la cesión total de la instrumentación económica a las Comunidades Autónomas. De este modo, se ayudaría a evitar los desequilibrios territoriales existentes en la actualidad, en materia urbanística, debiéndose promover, a través de la instrumentación económica establecida por Ley, que parte de los ingresos reales obtenidos las ventas de viviendas o suelo estén destinados a la prevención o regeneración de la naturaleza, y, en los cálculos realizados para obtener el precio final del suelo o de una vivienda se tenga en cuenta el daño real o, al menos, el ponderado que se estos impactos puedan generar al medio ambiente. Pensamos que es de notable importancia incluir entre la instrumentación económica tributos ambientales, tales como impuestos a la construcción, tasas de recalificación del suelo,..., con el fin de mitigar los efectos adversos de estos sobre el propio suelo, en general, y el medio ambiente, en particular, penalizando o sancionando los procesos especulativos, en los que el uso privativo del suelo incida, directa o indirectamente, en la propia actividad económica. Lo expuesto anteriormente, grosso modo, se mantiene en el R.D. legislativo 7/2015, si bien, el fondo se analizará en ulteriores estudios. 


\section{CONCLUSIONES}

De la investigación anterior dimanan las conclusiones siguientes:

$1^{\text {a }}$. Primera conclusión: Tras la aprobación de la actual Ley del Suelo, nos encontramos ante un modelo territorial y urbano, que acaba con el arcaico patrón de ciudad dispersa, como consecuencia de una nueva economía basada en la terciarización, la diversificación y la flexibilización de las actividades económicas, los bienes y servicios, y la incorporación, tanto en las economías domésticas como en las empresas, de las nuevas tecnologías de la información. Así, pues, pensamos que se están generando nuevas formas de hacer ciudad en las que la especialización espacial, la recalificación urbana, la dispersión en el territorio o la reorganización productiva han creado y crean nuevas formas de vida urbana y de los instrumentos de planeamiento e intervención en el territorio.

$2^{a}$. Segunda conclusión: El Real Decreto Legislativo 2/2008, de 20 de Junio, y que se mantiene en el Texto Refundido de la Ley del Suelo Real Decreto Legislativo 7/2015, introduce de forma novedosa, respecto de las Leyes del Suelo anteriores, la incorporación de las bases ambientales de la sostenibilidad en la ordenación y uso del suelo, tal y como establece la política de la Unión Europea. De hecho, la Ley distingue una nueva tipología de suelo, a tenor de la las políticas europeas, orientadas a la protección y conservación del medio ambiente; el suelo se entiendo como "un recurso natural, escaso y renovable". Se introduce una nueva tipología se suelo, de notable importancia a la hora de establecer los instrumentos económicos, dejando de hablar de clases para referirse a situaciones básicas del suelo, distinguiéndose "suelo rural" y suelo urbanizado (se elimina, al menos dentro de la clasificación, aunque no en su esencia, el suelo urbanizable).

$3^{\text {a }}$. Tercera conclusión: De forma concreta, el "impuesto sobre Transmisiones Patrimoniales y Actos Jurídicos Documentados", como instrumento económico, nos presenta una problemática que emana de dos cuestiones fundamentales; la primera de ella, es el ámbito dentro del impuesto, ya que se creaba confusión a la hora de estipular si el impuesto afecta a las Transmisiones Patrimoniales Onerosas o solo a los Actos Jurídicos Documentados; la segunda cuestión, es el alcance las operaciones exentas, puesto que se entiende que beneficia las adjudicaciones y aportaciones propias de la actuación en una operación de reparcelación, pero no queda igual de claro respecto de las segregaciones, expropiaciones forzosas o las agrupaciones.

$4^{a}$. Cuarta conclusión: Tal y como hemos podido analizar a lo largo del presente trabajo, la Ley del Suelo ha incorporado como uno de sus ejes fundamentales, la protección vs. conservación del medio ambiente, si bien, entre sus instrumentos económicos no cedidos, tan solo han destacado los ITP y AJD, y los precios del suelo. Con lo que podemos deducir que estos no eran la "columna vertebral" o la instrumentación primaria con la que desarrollar la actividad del sector de la construcción en pro de la conservación de la naturaleza. De igual modo, tras todo lo expuesto con anterioridad si que podemos deducir que suponen la estructura principal para la obtención de dichos fines.

\section{REFERENCIAS}

Berges, A. y Ontiveros, E. (2007). La nueva Ley de Suelo desde la perspectiva económica. Sostenibilidad y eficiencia en los Mercados del Suelo. Ciudad y Territorio, Estudios Territoriales, XXIX (152-153), 259275. Recuperado de http://www.afi.es/EO/CyTET-152-02-Ontiveros.pdf

Bouazza Ariño, O. (2006) ¿Vale todo en el urbanismo? Ecosostenible, 15, 23-32.

Bouazza Ariño, O. (2009). Ordenación del litoral y abusos urbanísticos (el caso valenciano). Revista Aragonesa de Administración Pública, 34, 255-283. Recuperado de http://www.aragon.es/estaticos/ GobiernoAragon/Organismos/InstitutoAragonesAdministracionPublica/Documentos/docs/ Instituto\%20Aragon\%C3\%A9s\%20Adm\%20P\%C3\%BAblica/Revista\%20Aragonesa\%20Adm\%20 P\%C3\%BAblica/Revista\%20completa\%2032\%20jun\%202008+/Numero_34/06\%20Bouazza.pdf

Constitución Española (BOE núm. 311, 29 de diciembre de 1978).

Fariñas Tojo, J. (2007). Las nuevas bases ambientales de la sostenibilidad en la ordenación y utilización del suelo. Ciudad y Territorio, Estudios Territoriales, XXIX (152-153), 291-300. Recuperado de http://bases.cortesaragon.es/bases/NDocumen.nsf/0/b0a4b5d8e7244e83c12573f400409aab/\$FILE/ Farina\%20Tojo.pdf

Font Arellano, A. (2006). La explosión de la ciudad: transformaciones territoriales en las regiones urbanas de la Europa Meridional. Madrid: Ministerio de Vivienda. 
García Montalvo, J. (2000). El precio del suelo: La polémica interminable. En García-Milá, J. (Ed.). II Jornada sobre Nuevas Fronteras de la Política Económica. Barcelona: Centre de Recerça en Economía Internacional. Recuperado de http://crei.cat/research/books/1999(SU).PDF

Ley 6/1998, de 13 de abril, sobre régimen del suelo y valoraciones (BOE núm. 89, 14 de abril de 1998).

Ley 9/2006, de 28 de abril, sobre evaluación de los efectos de determinados planes y programas en el medio ambiente (BOE núm. 102, 29 de abril de 2006).

Ley de 12 de mayo de 1956 sobre régimen del suelo y ordenación urbana (BOE núm. 135, 14 de mayo de 1956).

Martín Mateo, R. (2007). La gallina de los huevos de cemento. Madrid: Civitas, Cizur Menor.

Matesanz Parellada, A. (2009). El suelo en la legislación urbanística española. Ciudades para un futuro más sostenible, 51, 1-25. Recuperado de http://habitat.aq.upm.es/boletin/n51/aamat.html

Mella Márquez, J.M. (2008). Explosión de la ciudad y ordenación del territorio en España: algunos apuntes. Clm.economía, 11, 165-199

Méndez Rexach, A. (2014). Presentación Por la rehabilitación, la regeneración y la renovación urbanas. Ciudad y Territorio, Estudios Territoriales, XLVI (179), 5-9. Recuperado de http://www.fomento.gob.es/ NR/rdonlyres/A1D324C8-BF2F-4985-899E-17AEA3C209E2/124396/ExtractoCyTET_179.pdf

Ministerio de Obras Públicas, Transportes y Medio Ambiente (1996). Informe sobre Suelo y Urbanismo en España. Madrid: Comisión de Expertos sobre Urbanismo.

Pérez Martínez, T. (2009). Principales modificaciones para 2009 en la regulación general de los impuestos cedidos a las comunidades autónomas. Tributación, 127, 21-46. Recuperado de http://www.fiscalimpuestos.com/files-fiscal/Tributacion\%20127.pdf

Real Decreto Legislativo 1/1992, de 26 de junio, por el que se aprueba el texto refundido de la Ley sobre Régimen del Suelo y Ordenación Urbana (BOE núm. 156, 30 de junio de 1992).

Real Decreto Legislativo 1/1993, de 24 de septiembre, Texto Refundido del Impuesto sobre Transmisiones Patrimoniales y Actos Jurídicos Documentados (BOE núm. 251, 20 de octubre de 1993).

Real Decreto Legislativo 2/2008, de 20 de junio, Ley del Suelo (BOE núm. 154, 26 de junio de 2008).

Real Decreto Legislativo 7/2015, de 30 de octubre, por el que se aprueba el texto refundido de la Ley de Suelo y Rehabilitación Urbana (BOE núm. 261, 31 de octubre de 2015).

Roca, J. y M. Burns (1998). La Liberalización del Mercado del Suelo en España. Madrid: Reforma de la Legislación Urbanística de 1998, Catastro.

Sotelo Navalpotro, J.A. (1999). Modelos de Organización y Desarrollo Regional. Madrid: Oxford University Press.

Sotelo Navalpotro, J.A., Tolón Becerra, A. y Lastra Bravo, X. (2011). Indicadores por y para el desarrollo sostenible, un estudio de caso. Estudios Geográficos, LXXII (271), 611-654. Recuperado de http:// estudiosgeograficos.revistas.csic.es/index.php/estudiosgeograficos/article/view/356/355

Sotelo Navalpotro, J.A., Sotelo Pérez, M. y García, F. (2013). Water Supply and Water Footprint in the Urban Region of Madrid (Spain). International Journal of Business and Social Science, 4, 23-28. Recuperado de http://ijbssnet.com/journals/Vol_4_No_11_September_2013/3.pdf 